\title{
Data Seeking Behavior of Economics Undergraduate Students An Exploratory Study
}

This article investigates the information seeking behavior of undergraduate economics students to determine their effectiveness in locating data sets for a multiple regression analysis assignment and seeks to discover how students pursue the process of learning to find and use data. A study was conducted in fall and spring 2015 to find out (1) what influences affect students' ways of seeking data sets; and (2) what changes occur over the course of students' data search. The findings say that while only about $10 \%$ of students started with the library, either a library database or a librarian, nearly half eventually used the library in some form for this course project. The conclusion reached as a result of the survey was that undergraduates have widely varying data search concepts, that more of the students look for personal interest data than business discipline data, and that the searching part of economics students' first regression project can add a noticeable amount of time to the assignment before they can even get started working on the regression itself. Included are ideas for further research and ways to reach students before data searching gets frustrating, as well as thoughts on how to structure data search learning and how to use insights into student behaviors to overcome the reluctance of some faculty.

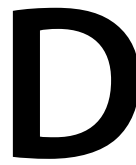
ata are everywhere. It is impossible to get through the day without hearing about so-called alternative facts with misused statistics, seeing an infographic or chart to explain a theory or trend, or studying data as proof of a concept, either on television news, online news, on Facebook, or on websites visited frequently. Quantification adds clarity to our often confusing, disorganized, and increasingly interdependent world.

In order for undergraduate students at university to be considered welleducated and highly employable for consideration of the best paying jobs in today's employment market, they must be data literate, "the ability to understand and use data effectively to inform decisions."

Data skills are considered mandatory in many fields of employment. ${ }^{2}$ Economists, for example, use data to offer solutions for problems in government, international trade, finance, the environment, agriculture, immigration, climate change, and more. Students pursuing an economics degree are required to show proficiency in working with data. As economists, following graduation, they will be

\section{Betty Garrison and Nina Exner}

Betty Garrison (bgarrison@elon.edu) is the Business Research Librarian at Elon University. Nina Exner (nexner@ vcu.edu) is the Research Data Librarian at Virginia Commonwealth University.

Reference \& User Services Quarterly, vol. 58, no. 2, pp. 103-113 (c) 2018 American Library Association. All rights reserved.

Permission granted to reproduce for nonprofit, educational use. 


\section{FEATURE}

dependent on those data skills to a greater degree than in many other professions.

A study was conducted in 2015 at Elon University, a midsized private university in the Piedmont region of North Carolina, with economics undergraduates in a required statistics course to find out how the students search for data sets on self-selected topics to complete a required regression analysis assignment. The authors hoped to find out what influences affect students' ways of seeking data sets, and what changes occur over the course of students' data research. Our intention was to better understand what affected how often students were successful finding the anticipated data set on their own and use that insight to understand ways to optimize data literacy interventions from a librarian.

\section{BACKGROUND: THE IMPETUS FOR THE SURVEY}

A few economics undergraduate students per semester find the business librarian's office, usually after stopping by the information service desk in the library to ask for help finding data sets for their class, ECO 203 - Statistics for Decision-Making. A typical student usually begins the research interview by saying that he has already spent hours looking for relevant data sets, has been unsuccessful, and is hopeful the librarian can help him. Often the librarian can elucidate the information request and provide the resource needed in short order.

Data reference interviews require special skills. ${ }^{3}$ Unlike most reference interactions, data reference interviews involve significant discussion back and forth between student and librarian regarding what data the student hopes to find, what he hopes to prove with it, and articulating the boundaries surrounding the types of data he requires, including time or date range, geographic location, whether data sets or statistics, the units of analysis, and the type of data, for example demographic or financial.

Ideally, an economics professor teaching a statisticsheavy research methods course would request the economics liaison librarian's collaboration on the section of their course that requires students to locate and manipulate a data set, especially considering the complex and often laborious nature of locating data. The professor describes the data assignment, in this case a regression analysis, explains how the assignment broadens the students' knowledge of the subject matter, then requests not only the librarian's expertise and assistance in formulating the assignment, but also requests data literacy instruction in the classroom.

For the eight sections of the course ECO 203, the assistance of the economics liaison librarian was not requested. By not collaborating in the classroom, the opportunity to enlighten students about search strategies for data information retrieval was missed. As noted previously, the importance of data literacy in being an informed citizen, in making life decisions, and in competing in the job market cannot be overstated. MacMillan writes, "As research in many fields becomes increasingly dependent on large data sets, librarians need to make students aware of these resources as part of their information environment, to better prepare them for graduate work and/or their working careers."

What's more, a great deal of valuable time is lost for faculty, librarians, and students by not cooperating during the planning, learning, and execution stages of research. The cost/benefit analysis of information seeking and time constraints, and factoring in the waste of time, resonates with undergraduate students. When faced with any assignment requiring research from secondary sources, students will often weigh the merits of time spent seeking information with the finite amount of time available to complete the assignment and, as humans, the amount of time available for other pursuits. ${ }^{5}$

The catalysts for the study were curiosity about student data search habits and what the findings from a survey might achieve to bring about more collaboration in the classroom. We examined syllabi from 2 professors' course sections which offered insight into how students are directed to begin their data research. When offering advice to students about the process, one professor teaching the economics course wrote on her syllabus that it was not her job nor that of the library staff to do the students' research. She also suggested that a Google search might find the appropriate data. Another professor on her syllabus mentioned the business research librarian as a good resource. On the syllabi of these two professors, library databases and resources were mentioned as possible data depositories while offering no specific resources by name.

The assignment instructions included language promoting use of library resources, but students could choose to conduct their search however they wanted. The professors offered advice about how to conduct data research:

- Professor l's assignment advice from their syllabus:

- "There is a good chance the data is available through one of the library databases."

- "Try doing a Google Search on your topic. A lot of data is available on the web."

- "Please keep in mind that it is your responsibility to collect your data. If you need data that is business, economic, or financial in nature, I may be able to point you in the right direction, however it is not my job (nor any of the library staff) to find data for you. This is part of the assignment."

- Professor 2's assignment advice from their syllabus:

- "Elon has a considerable number of data resources. Betty Garrison in the Library is a wonderful resource."

\section{LITERATURE REVIEW}

Undergraduate students have not been exposed to most of the topics they encounter at university and are not expert searchers. Partlo notes, "Since undergraduates are emerging as researchers they do not have experience to guide them in 
areas more experienced researchers take for granted." When they approach research on an unfamiliar topic, they have few familiar resources to draw on to begin their research, not having accomplished the level of knowledge that comes with advanced studies, only what they have recently been exposed to in the classroom, according to Leckie. ${ }^{7}$ She says that students "do not think in terms of an information-seeking strategy, but rather in terms of a copying strategy." Kellam relates that while students in a social sciences research methods class might be taught how to analyze data, "they leave the class without having gained the ability to find data on their own." The result is that data search and discovery is a serious challenge for some students and that they often come to it without guidance.

It is not good enough to just be information literate. Stephenson explains that in order to grasp the concepts being taught and develop critical thinking skills in the social sciences, students must become data information literate and understand numerical concepts as "an integral component of information literacy for these disciplines." ${ }^{\prime 9}$ To go further, students will utilize their learned data literacy to become more informed citizens. Successful data interpretation can lead to progress in political discussion, community building and issue awareness and debate. ${ }^{10}$

Accessibility is of paramount importance to the student researcher. Kim says, "Inaccessibility might be a critical barrier to the use of sources that might otherwise be appropriate for a particular task." ${ }^{" 11}$ Unfortunately, the current disorganized nature of data storage is such that discoverability for the data illiterate undergraduate student is difficult or impossible without the benefit of some data literacy instruction or possibly the mentorship of a data-knowledgeable librarian or educator.

Students don't necessarily view library resources or the librarian as convenient or the first place to start their data research. Of primary importance to students is the convenience factor of an information source and cannot be overstated. ${ }^{12}$ Gravitation towards a search engine as a starting point can be surmised because search engines are convenient and students know how search engines work. ${ }^{13}$

Numerous studies have been conducted by librarian scholars to discover how faculty view librarians and why they aren't interested in collaboration. ${ }^{14} \mathrm{~A}$ review of the literature found reasons to be varied, including no sufficient subject expertise, librarians are seen as auxiliary services only, students are capable of locating relevant research on their own or they already have the necessary skills, students have been given adequate information literacy instruction previously, there isn't sufficient time in a crowded class schedule to include a subject librarian, lack of faculty awareness of librarian information instruction or they themselves provide research instruction, or simply difficulty scheduling a class research session with a librarian.

Frequently, the lack of collaboration between librarians and faculty leads to a vacuum in student information literacy. Learning occurs in scaffolding, building layers of knowledge over time. But without integrating information literacy and data literacy skills into classroom curriculum, students are not being exposed to information research methods that work, that save time, and that are efficient. One successful way to influence students to seek the advice of an information professional is for faculty to advocate the value of consulting university librarians. ${ }^{15}$

A review of the literature finds a dearth of analysis on the data research methods of undergraduate students, much less researchers as a whole. But all data researchers, whether undergraduate or skilled professional, face similar data discovery problems. Researchers often search for data that has never been created, the data may lack the necessary conditions like time period or geography, reviewing multiple data sets from various sources can waste valuable time, the data archive being searched might not house the data, and time spent searching leaves less time for researchers to further their research. ${ }^{16}$

The motivations of the undergraduate data researcher will vary somewhat from that of more experienced researchers in several ways. They may have a class project to locate data on topics that they did not choose, and they may be working on a shorter time frame assignment. And students might only need to locate a certain numerical count of data for use on a statistical assignment and not need to focus on the subject matter of the data. This makes it critical that novice data researchers get advice and assistance, and greatly improve their data research results with the benefit of at least an introduction to data literacy.

\section{METHODS}

This study was driven by the overall research question, "How do economics students pursue the process of learning to find and use data?" This question was looked at in three ways, by examining: (1) what influences affect students' ways of seeking analyzable data sets; (2) how does working with the library affect the process of learning to work with data; and (3) what changes occur over the course of students' work with data searching?

The study was conducted in the spring of 2015 and again in late fall semester 2015. The participants of this study ranged from freshmen to juniors. This study sought to explore the information seeking effectiveness of the students after at least one session searching for data sets to extract data for their case analysis.

A survey was administered to students in eight sections of ECO 203, "Statistics for Decision Making." This survey was reviewed and approved through the campus Institutional Review Board. The survey was distributed electronically after the students completed their final assignment. Students were not required to answer the survey, and they did not receive any inducement for participation.

Students majoring in economics at Elon University are required to take the course "Statistics for Decision-Making." 


\section{FEATURE}

Students in eight sections of this course complete, as their final assignment, a multiple regression analysis paper involving several datasets with one dependent and three independent variables. Datasets had to be substantial instead of small personal surveys, with at least 30-35 observations in the dataset. Topics were not assigned, and students had the latitude of choice.

All students in eight class sections taught by two professors were asked to participate in this survey. All participants had completed an assignment to search for a dataset and answer a question using variables from that dataset. The survey, included as appendix 1, was filled out in specific reference to this assignment. Participation was voluntary and all questions were optional. Out of the 230 students, 178 completed enough of the survey to be included in one or more of the analyses. So our response rate was 77 percent, which is high enough to think that the responses represent the population of all students taking this class.

Most responses were analyzed with graphs and descriptive summaries. A question about time spent searching was converted from categories to a scale for inferential analysis. An open question about the student's research topic was coded inductively for topic area and like topics were synthesized. No participants were excluded, but incomplete responses were excluded for descriptive and thematic analyses as well as any statistical test where one or both variables in the test were unanswered. Please note, that means that the $\mathrm{n}$ for each question varies due to partial responses. To help preserve overall privacy, we did not collect demographics or other personal data.

\section{RESULTS}

\section{Ways of Seeking Data}

It was most important to us to understand students' information-seeking interests. Students were encouraged by their professors to try to find appealing datasets. Therefore, one of the survey questions was "What factor most influenced your research topic choice?" Understanding students' data

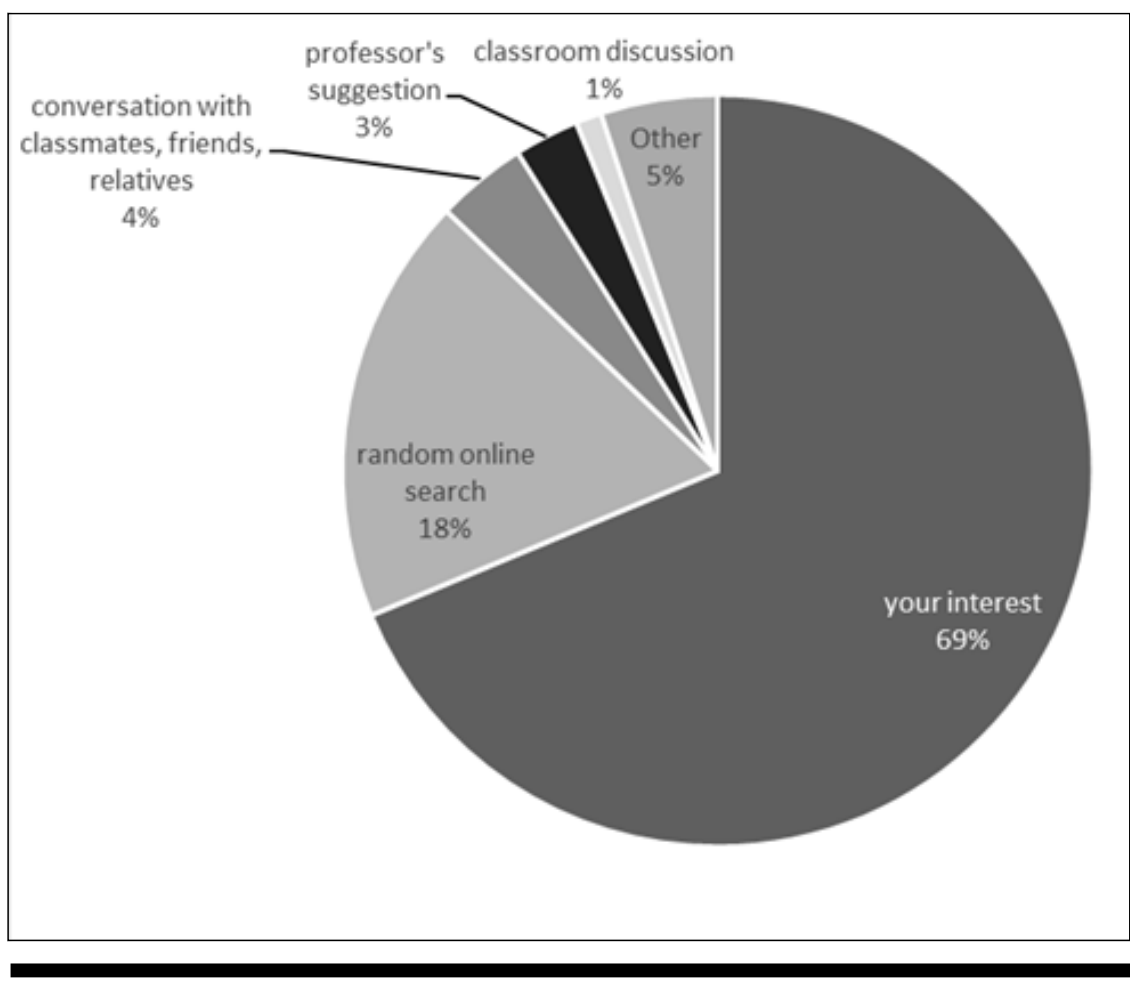

Figure 1. What factor most influenced your research choice?

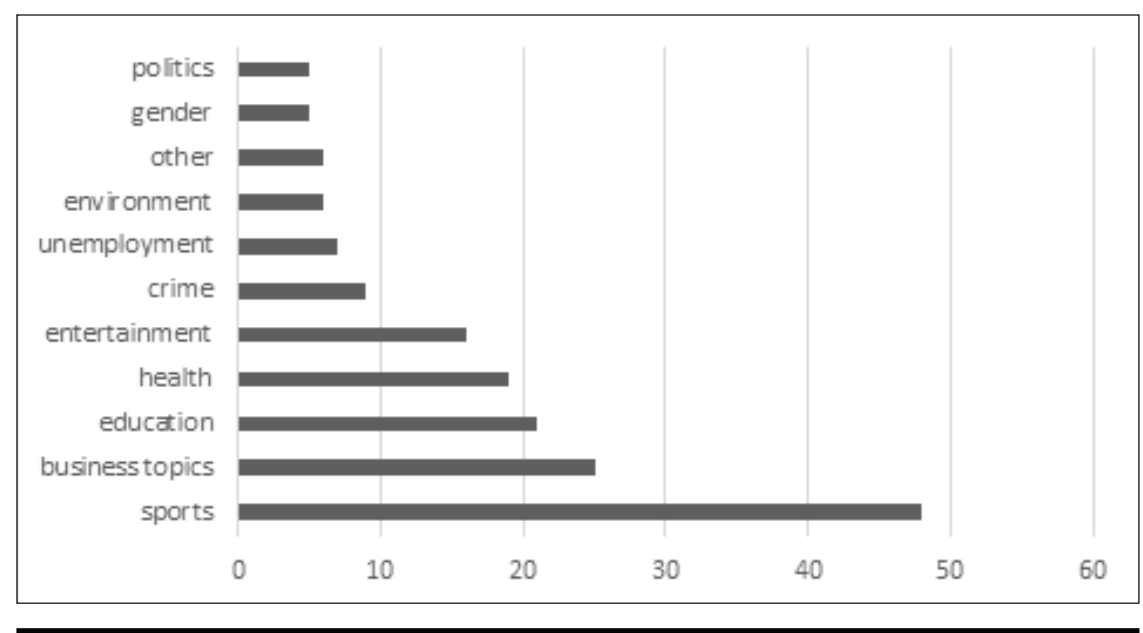

Figure 2. Most popular data topics

interests could help make examples and projects more engaging to students in the future. Figure 1 summarizes responses about what factors influenced their topic choices.

Students had many different topics of interest, many of which were unique or specific to that student. However, some topical themes did emerge. Figure 2 summarizes themes of topics where the students replied what their final topic or question ended up being. From these results, we see that personal interests were the most common topics, with "random" web searches the next most common.

Another important question about data-seeking is how long it took to find a usable dataset. The amount of time 
taken can tell us how long to expect similar projects to take, and it sets a benchmark for comparison in future studies. Table 1 summarizes the overall distribution of time taken in the project.

A third question about data-seeking is how students began their data search. Students took different ways to start looking for their data. Understanding what sources the students started with gives us insight into how data strategies are first applied by students. That helps us to understand what they find instinctively easiest or most comfortable. Figure 3 summarizes the students' initial data search strategies.

Most students took an hour or less to find a dataset for their dependent variable, but around a third took more than an hour. Search engines were the most common starting place, followed by specific websites the students already knew.

\section{Working with the Library}

As the data above shows, around 10 percent of the students started with the library (either a library database or a librarian). Over the course of their searches, however, nearly half eventually used the library in some form. Figure 4 shows the change from whether students used a librarian or library database as their first source in searching for their data, to those who received help from the library at any point during their data search.

The impact of working with the library on time was tested. Table 2 shows the results of the $\chi^{2}$ test (calculated in SPSS 24.0.0.2). With a significance of $p=0.719$, no significant difference at the 0.05 level was found between users of the library via databases or consultations and non-users of the library. A summary crosstab shown in table 3 shows the distribution of time across users and nonusers of the library, with slightly greater numbers of non-library-users in the shorter times and a slightly larger number for the longer times.

\section{Issues During the Data Search}

Another issue to be investigated was whether students encountered troubles during their data search. To investigate that, we asked two survey questions: (1) "Did you have difficulty finding data for your dependent variable?" and (2) "Did you change your topic at any time during the research phase?"

As figure 5 shows, just over half of the students (94, or 53 percent) did not report difficulty or change their topic while searching for data. 27 students (15 percent) had difficulty finding data but did not change topics. 29 students
(17 percent) changed their topic at some time while researching but did not report difficulty in finding data. A final 27 students (15 percent) reported both difficulty finding data and having changed their topic over the course of the research project. Two students did not complete both questions on the survey.

Overall, students who reported difficulties started similarly to those who did not, but with a few noticeable differences. Figure 6 shows the starting strategies of students who encountered difficulties. The most noticeable difference is that a much lower percentage of students started with a specific website. Proportions of students who started with search engines and library databases were higher than the same proportions among the respondents overall. Figure 7 shows the same proportions, as a chart alongside the proportions of the starting sources of students who did not report difficulty finding data. The overall shares of resources

Table 1. Frequencies of time spent searching

\begin{tabular}{|lc}
\hline $\begin{array}{l}\text { How much time did you spend searching } \\
\text { (total) for your dependent variable? }\end{array}$ & $\begin{array}{c}\text { Responses } \\
(\mathbf{N = 1 7 8 )}\end{array}$ \\
\hline 0-30 minutes & $66(37 \%)$ \\
\hline 31-60 minutes & $50(28 \%)$ \\
\hline $61-90$ minutes & $22(12 \%)$ \\
\hline 91-120 minutes & $14(8 \%)$ \\
\hline $121-150$ minutes & $11(6 \%)$ \\
\hline $151-180$ minutes & $3(2 \%)$ \\
\hline 180 minutes & $12(7 \%)$ \\
\hline
\end{tabular}

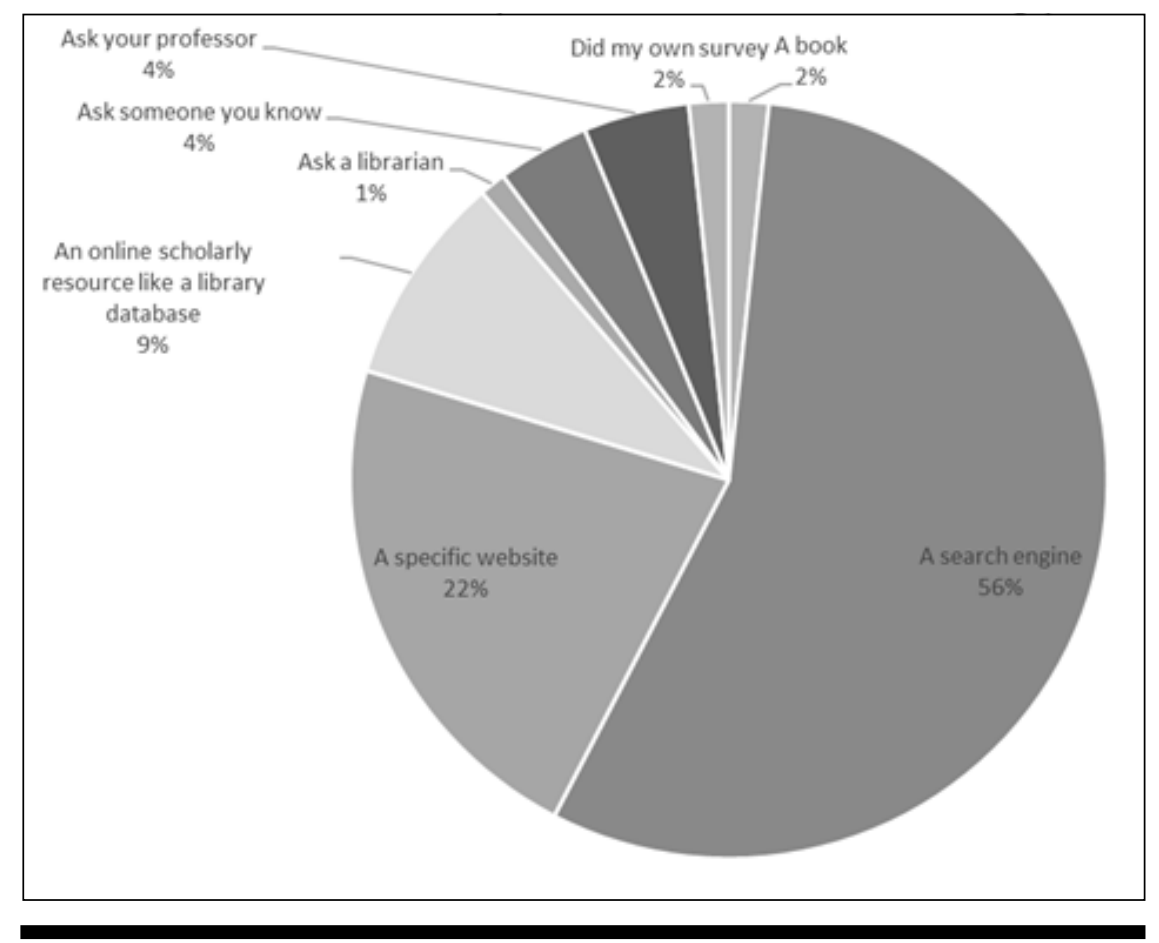

Figure 3. What was your first method of researching your topic? 


\section{FEATURE}

used are similar, but noticeably students with difficulties had higher percentages of trying specific websites and asking someone they knew.

Students stating that they changed topics were asked to (voluntarily) explain why they changed. Forty of the students that had changed topics gave reasons similar to, Not enough data on my original topic (including variations in phrasing such as not enough information on first topic). A very few gave further explanation, such as:

The data for my previous topic was harder to convert to excel and much harder to read. My newer topic was easier to find data for and it was already in Excel.

I had tried and researching numerous topics. I wasn't sure about how to effectively execute the research process. I assumed you would be able to pull an entire data set but in reality we needed to manually enter our data.

It was hard to find statistics on animal abuse there was percentages but I couldn't find a website that had the cases. So I switch back and forth with different ideas until I decided to stick with my original idea [animal cruelty crimes].

\section{DISCUSSION}

Although the students in the survey all started from a similar level of datasearch instruction or lack of, they used many strategies to start looking for data. The responses indicate that students use a combination of Googling or personal past experience in a topic area and most students started with a search engine or a specific website. Not many students started with the library, but close to half turned to the library at some point. This puts the burden on the students and seems inefficient. We suspect that there is a more strategic way to embed data search and data use into the course so that students are developing their ideas of what data looks like and where it can be found alongside the process of learning what to do with the data. Librarians at other institutions have found success as the conduit to

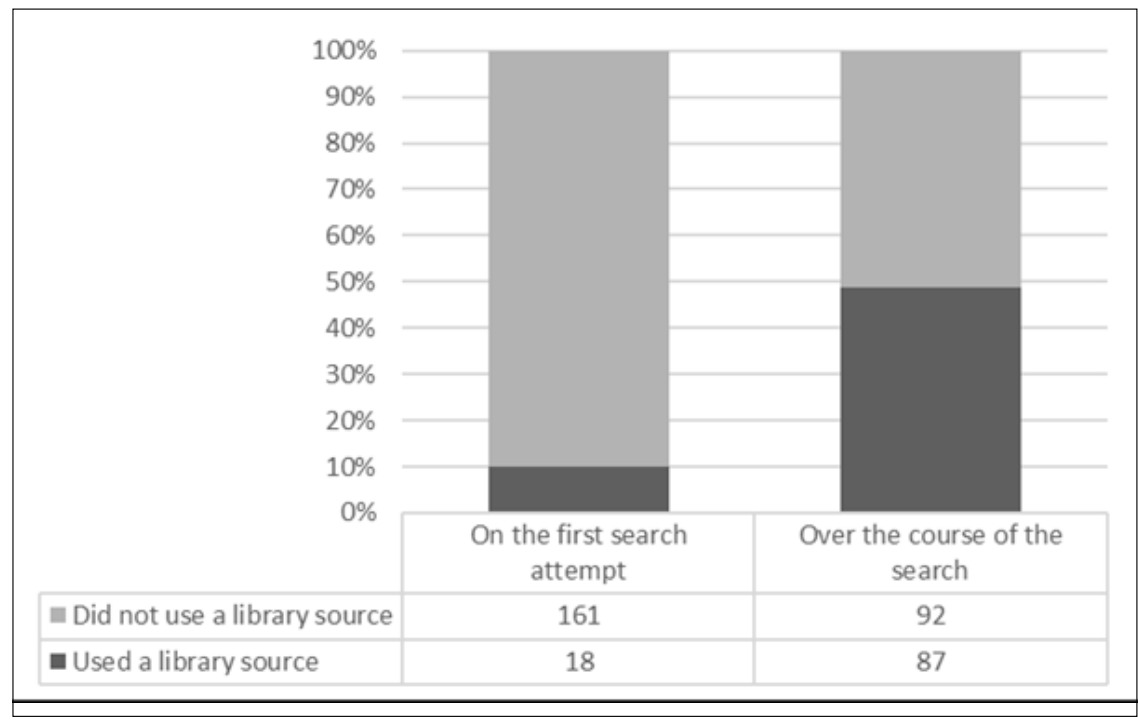

Figure 4. Started with library sources versus used library sources in the data search

Table 2. Chi-Square test of time spent searching

\begin{tabular}{lccc} 
& Value & df & $\begin{array}{c}\text { Asymptotic } \\
\text { Significance } \\
\text { (2-sided) }\end{array}$ \\
Pearson Chi-Square & $3.687^{\mathrm{a}}$ & 6 & .719 \\
Likelihood Ratio & 3.724 & 6 & .714 \\
Linear-by-Linear Association & 1.982 & 1 & .159 \\
N of Valid Cases & 178 & & \\
\hline
\end{tabular}

a. 2 cells (14.3\%) have expected count less than 5 . The minimum expected count is 1.47 .

Table 3. Time spent searching, by users versus nonusers of the library

\section{How much time did you spend searching (total) for your dependent variable?}

0-30 minutes

31-60 minutes

61-90 minutes

91-120 minutes

121-150 minutes

151-180 minutes

$>180$ minutes

Total
Did you use a librarian or library database? (composite variable)

\begin{tabular}{ccc} 
Yes & No & Total \\
37 & 29 & 66 \\
27 & 23 & 50 \\
9 & 13 & 22 \\
7 & 7 & 14 \\
5 & 6 & 11 \\
2 & 1 & 3 \\
4 & 8 & 12 \\
91 & 87 & 178 \\
\hline
\end{tabular}

student learning in data literacy by approaching faculty with a variety of classroom instruction options, related learning outcomes and meaningful assessment goals. ${ }^{17}$

According to the survey, many students looked for data on personal, not scholarly, interests. Even business topics were relatively few as one might assume that business school students would have more business-related interests. 
Therefore, examples and practice activities involving data should include popular topics like sports and entertainment, as well as relevant student concerns like tuition and employment. Libraries can assist by adding datasets and data resources that provide data of interest to students. These are not always the same datasets that faculty would recommend because their interests are so different. Data collection policies need to balance faculty research interests with engaging topics that students can use to understand the personal value of data.

Close to half of the students either changed their topics or had difficulty with their search. Students who reported difficultly with their data search were less likely to have started with a specific website than the students who had an easier time locating data. This adds to the idea that a more strategic involvement of the library with economics courses is needed. But it also points to a trade-off: students could start with a more limited choice of data such as a specific website to learn what to do with data, or they can learn to work with data the way that it really occurs even when that means messy or unsatisfying data.

An important factor for this particular course is understanding that if students need a certain number of variables (in this case 4 variables), they probably need to find a single table or dataset that has that many variables all in the same table or dataset. The librarian must also be familiar with some useful databases and websites for data. Twenty-two percent of our participants used specific websites to start with; we consider this a valuable strategy and believe that more students would benefit from starting with specific data websites such as the American Community Survey Public Use Microdata Sample.

We suggest that a scaffolded strategy could be used for librarians to collaborate with interested faculty and to teach data literacy. The amount of in classroom time or the level of embedding would determine how much could be accomplished. A series of short face-to-face sessions during class time would be the best scenario, but it might be easier in some cases to design this collaboration around online videos and formative assessments as exercises to help the students work through the process on their own time or to use those in conjunction with in-class instruction. The format, goals, and scope are all parts of the planning discussion to have between the librarian and the faculty member when collaborating on a data literacy classroom session. Regardless of format, we propose the following steps:

1. Identify a dataset with microdata (also called case-level data) available on a range of student-friendly dependent variables. If the library subscribes to datasets, those are a good starting point. If not, the IPUMS data at https://www.ipums.org/ might be a good choice if two or more full class sessions are available for practice. If not, the ACS PUMS data would be a faster alternative requiring less hands-on exploration and set-up time from students.

2. Create a demo of an example question. This should be centered around topics that students are interested in like sports, entertainment, student life or social issues.

3. Present (or record) the demonstration. Include how to find the dataset and qualities of the dataset that make it useful or interesting. Demonstrating the search process would also be valuable. For example, compare a search for data on business jobs versus microdata on employment site: gov.

4. Have students do a series of tasks in order. The exact tasks will depend on the faculty instructors' goals but breaking down the subtasks and performing a formative assessment would keep students on track for success.

5. Task series example:
a. locate the dataset and codebook
b. choose the exact variables
c. download the dataset
d. create a cross-tabulation
e. create a regression.

6. Finally, assign a data analysis (as a summative assessment) where students produce and interpret a regression.

Some of the steps are more clearly in the realm of the work of the faculty instructor and other parts would be covered by the librarian during the in-class or online instruction 


\section{FEATURE}

but there is overlap and areas for collaboration. For example, the librarian and faculty member might choose a dataset together and discuss the demo question before class. The librarian might present the demo question, search process, and lead the students in finding the dataset and working with the variables during a hands-on session. The faculty instructor might participate in teaching the students about choosing variables and creating a cross-tabulation and regression. In this way the faculty and librarian reinforce each other and if questions arise during the use of the data set the faculty member can clarify the statistical concepts. The final data analysis assignment is likely the final project or a step toward the final project and is designed and assessed by the faculty instructor.

Acknowledgement in a class course management system like Moodle or Blackboard is another effective way for the librarian to be included. ${ }^{18}$ The librarian can post a discussion board thread for students to ask questions and for the librarian to share ideas and suggestions with the class. This gives students advice on easier, faster ways to get their data search started and concluded so that they can concentrate on practicing the data analysis they are supposed to be learning. Of perhaps the greatest benefit to librarians in reaching students is the faculty endorsement, whether in a classroom collaboration, in a class course management system, or in consultation. Including the librarian in the classroom would help students save time, even if it is only for a brief introduction to data resources.

At some point, students will need to learn to work with data "in the wild."

The proportion of students that had to change their topics makes us wonder what the best road to data literacy is. Is it better to start students with controlled datasets to understand how variables relate to each other first or is it better to start with real data-as these classes did - and learn to find and work with it as the data really exists? Much of the current literature on data literacy practice suggests easing students in to working with data such as having students in a data literacy session evaluate specially selected resources. ${ }^{19}$ This study was not designed to test different approaches but this question arose as we assessed our data. We see this as another area of data literacy instruction research that is needed. Learning that data is not always available for every

question is a valuable lesson and one which students at some point need to know to be truly data literate. Fully data literate students need to be able to compose a plausible data question and recognize usable datasets "in the wild."

Even if employing a guided and scaffolded strategy as previously described, it would be wise to follow-up with a hands-on exercise searching for datasets that are not from a predetermined source. A formative assessment after this search assignment can help show whether students are still on-track with learning goals. After adjusting trajectory and giving any needed assistance, the students would be more prepared for the graded assignment of finding and analyzing their research question. 
The overall time taken by students in locating data seems to point to a need for more engagement between librarians, faculty, and students to create a more seamless connection. Millennial and post-millennial students value speed in their searching. Adding an hour or more of data discovery for just the initial phase of a homework task (not the regression that was the main point of the assignment) can become a barrier and a frustration. An hour may not seem like a lot of time but within the perspective of the very broad assignment finding any four variables should take far less than an hour. In another way of looking at it, that hour could have been a class hour where students not only get their four variables but also learn strategies to help in future tasks. This might be a more productive and less frustrating hour for students than time spent fruitlessly searching and changing their topics. Millennials are often underprepared for complex interpretation in their search tasks..$^{21}$ Because datasets involve the intersection of complex search with data literacy, librarians and faculty need more effective ways to integrate these tasks.

This study also informed about students' data interests such as careers, sports, and student life. Identifying these interests can help with data resource purchases by the library and populating research guides. Using popular topics to frame data instruction also is a good way to engage students, as mentioned earlier.

Data specialists and data non-specialists in libraries will need to work together to find new, effective ways to address challenges in search, subject outreach, and applying data.

\section{CONCLUSION}

The results of the survey tell us that undergraduates tend to take a leap into the data unknown by beginning their data discovery via a search engine and bypassing libraries and librarians. Thus, accessibility and convenience are chosen first over expert or knowledgeable guidance.

The disconnect between students and the library as the go-to knowledge bank can be attributed to, in large part, a failure of outreach concerning both data resources and librarians as an expert resource. It continues to be the responsibility of liaison librarians to initiate contact with their departments, with in-person contact providing the most effective results. More faculty interaction, especially good working relationships and focused outreach, will yield the highest rewards for gaining a collaboration with faculty. ${ }^{22}$ These interactions may start simply as acquaintance but can ultimately lead to mutually beneficial collaborations for the benefit of the students' research and possibly the faculty member's own scholarly output.

In the case of particularly difficult research such as data discovery, students would greatly benefit from a working session with a knowledgeable librarian. Because a substantial number of students were found to have challenges in their data search experience, including those who changed their topic because their searches were unsuccessful, we conclude that it would be a big benefit to students to have earlier access, specifically to data-knowledgeable librarians. Students having trouble with a data search who consult a librarian ideally get help not only with locating data but learn why their search was unsuccessful, whether it is because the search itself was flawed or because the data does not exist. These interactions become excellent teachable moments which benefit the student as well.

One of the challenges in this context is that Elon University does not have a data librarian. Subject librarians in this situation must have some basic data knowledge and data research skills. They also need to be made aware of the parameters of specific data assignments and how to address requirements such as finding a particular number of variables. Even for libraries with data librarians, other librarians are likely to encounter these questions if it is an assignment for a lot of students so training and information sharing among librarians is essential.

Beginning data literacy and learning among economics and business majors needs additional study. One of the challenges we had in interpreting our findings was that we are left without a good understanding of why students did what they did. Qualitative methods like interviews or search diaries would give us a richer understanding of what is happening with student searchers, both the efficient and the inefficient searchers.

Research into student data discovery needs is a much needed and neglected area of investigation at the intersection of (but different from) search behaviors and data literacy. This study is a single case and only beginning. Much of the research literature focuses either on data literacy instruction methods, expert researchers discovering data, or a focus on institutional data repositories. The gap in the literature is on the data search process of the novice. We believe that future investigation of data search will be especially useful as millennials and post-millennials pursue degrees for employment in newer data-driven business environments.

Finally, in the age of big data, librarians with strong information literacy skills but not quantitative backgrounds must increase their data skills in order to keep up with and to support data-focused coursework, data literacy, and data management. As data literacy expectations and use of data across disciplines grows, more research on how librarians without data specialties are experiencing and responding to these changes is needed. Librarians should remain engaged in this area and build knowledge and strategies to address the data needs of their community.

\section{References}

1. Ellen B. Mandinach and Edith S. Gummer, "A Systemic View of Implementing Data Literacy in Educator Preparation," Educational Researcher 42, no. 1 (January/February 2013): 30-37.

2. Thomas H. Davenport and D. J. Patil, "Data Scientist: The Sexiest Job of the 21st Century," Harvard Business Review 90, no. 10 (October 2012): 70-76; Cory Koedel and Eric Tyhurst, "Math Skills and Labor-Market Outcomes: Evidence from a 


\section{FEATURE}

Resume-Based Field Experiment," Economics of Education Review 31, no. 1 (February 2012): 131-40.

3. Kristin Partlo, "The Pedagogical Data Reference Interview," IASSIST Quarterly 33, no. 4 (Winter/Spring 2010): 6-10.

4. Don MacMillan, "Data Sharing and Discovery: What Librarians Need to Know," Journal of Academic Librarianship 40, no. 5 (September 2014): 541-49.

5. J. David Johnson, "Controlling the Flood: When More of a Dose Is Less," Journal of Documentation 70, no. 3 (2014): 330-45.

6. Partlo, The Pedagogical Data Reference Interview, 8.

7. Gloria J. Leckie, "Desperately Seeking Citations: Uncovering Faculty Assumptions about the Undergraduate Research Process," Journal of Academic Librarianship 22, no. 3 (May 1996): 201-8.

8. Lynda M. Kellam and Katharin Peter, Numeric Data Services and Sources for the General Reference Librarian (Oxford: Chandos, 2011), 49

9. Elizabeth Stephenson and Patti Schifter Caravello, "Incorporating Data Literacy into Undergraduate Information Literacy Programs in the Social Sciences: A Pilot Project," Reference Services Review 35, no. 4 (2007): 525-40.

10. Leanne Bowler et al., "It Lives All Around Us': Aspects of Data Literacy in Teen's Lives," 80th Annual Meeting of the Association for Information Science \& Technology, Washington, DC (2017), 27-35; Robert Gould, "Data Literacy Is Statistical Literacy," Statistics Education Research Journal 16, no. 1 (May 2017): 22-25.

11. Kyung-Sun Kim and Sei-Ching Joanna Sin, "Perception and Selection of Information Sources by Undergraduate Students: Effects of Avoidant Style, Confidence, and Personal Control in Problem Solving," Journal of Academic Librarianship 33, no. 6 (2007) 655-65.

12. Lynn Sillipigni Connaway, Timothy J. Dickey and Marie L. Radford, "'If It Is Too Inconvenient I'm Not Going after It:' Convenience as a Critical Factor in Information-Seeking Behaviors," Library and Information Science Research 33, no. 3 (2011): 179-90.

13. David Bawden, "Digital Libraries: To Meet or Manage User Expectations," Aslib Proceedings 58, no. 4 (2006): 346-54; Connaway et al, "If It Is Too Inconvenient I'm Not Going after it," 180.

14. Kate Manuel, Molly Molloy and Susan Beck, "What Faculty Want: A Study of Attitudes Influencing Faculty Collaboration in Library Instruction," Proceedings of the ACRL Eleventh National Conference, Charlotte, NC (April 10-13, 2003), 2; Claire McGuinness, "What Faculty Think: Exploring the Barriers to Information Literacy Development in Undergraduate Education," Journal of Academic Librarianship 32, no 6 (November 2016): 573-82; Kristin Anthony, "Reconnecting the Disconnects: Library Outreach to Faculty as Addressed in the Literature," College \& Undergraduate Libraries 17, no. 1 (January 2010): 79-92.

15. Judith Mavodza, "Information Seeking Behaviour of Library Users at Metropolitan College of New York," Reference Services Review 39, no. 4 (2011): 643-53.

16. V. M. Megler and David Maier, "Data Near Hear: Bringing Relevant Data Closer to Scientists," Computing In Science \& Engineering 15, no. 3 (May/June 2013): 44-53.

17. Katharine V. Macy and Heather L. Coates, "Data Information Literacy Instruction in Business and Public Health: Comparative Case Studies," IFLA Journal 42, no. 4 (2016): 313-27; Katharin Peter and Lynda Kellam, "Statistics \& the Single Girl: Incorporating Statistical Literacy into Information Literacy Instruction, LOEX Quarterly 40, no. 1 (2013): 2-3, 10.

18. Beth E. Tumbleson and John Burke, Embedding Librarianship in Learning Management Systems: A How-To-Do-It Manual for Librarians (Chicago: Neal-Schuman, 2013), 6.

19. Kellam, Numeric Data Services and Sources for the General Reference Librarian, 85; Stephenson, "Incorporating Data Literacy into Undergraduate Information Literacy Programs in the Social Sciences: A Pilot Project," 531.

20. Tibor Koltay, "Data Literacy: In Search of a Name and Identity," Journal of Documentation 71, no. 2 (2015): 401-15.

21. Lucy Holman, "Millennial Students' Mental Modes of Search: Implications for Academic Librarians and Database Developers," Journal of Academic Librarianship 37, no. 1 (January 2011): 19-27.

22. Larry Hardesty, "Faculty Culture and Bibliographic Instruction: An Exploratory Analysis," Library Trends 44, no. 2 (Fall 1995): 339-67; Paul Hrycaj and Michael Russo, "Reflections on Surveys of Faculty Attitudes toward Collaboration with Librarians," Journal of Academic Librarianship 33, no. 6 (December 2007): 692-96. 


\section{APPENDIX 1. ECONOMICS DATA RESEARCH STUDY}

Select your class section.
a. A
b. D
c. E
d. F
e. $G$

\section{Topic Selection}

What is your research topic for the data analysis assignment in Statistics for Decision Making (ECO 203)?

What factor most influenced your research topic choice? [choose one]

- textbook or assigned readings

- random online search

- classroom discussion

- your interest

- class lecture

- professor's suggestion

- conversation with classmates, friends, relatives

- other:

Did you change your topic at any time during the research phase?

- yes

- no

If you replied YES to the previous question, explain why you changed your topic. [free-text field]

\section{Conducting Research}

Which of these sources did you use when researching your topic? [Choose all that apply]

- a book

- ask a specialist in your topic field of study

- ask your professor

- a specific website

- ask a librarian

- search engine

- online scholarly resource like a library database

- ask someone you know

- other:
What was your FIRST method of researching your topic? [choose one]

- ask someone you know

- ask your professor

- a book

- search engine

- a specific website

- ask a librarian

- ask a specialist in your topic field of study

- online scholarly resource like a library database

- other:

\section{Dependent Variable Research}

How much time did you spend searching (total) for your dependent variable?

[choose one]

- 0-30 minutes

- 31-60 minutes

- 61-90 minutes

- 91-120 minutes

- 121-150 minutes

- 151-180 minutes

- More than 180 minutes

Did you have difficulty finding data for your dependent variable?

- yes

- no

Name the source of the dependent variable dataset you used for the class Statistics for Decision-Making. [free-text field] 